\title{
LITERATURA DE CONTROVERSIA RELIGIOSA JUDÍO-CRISTIANA MEDIEVAL EN PORTUGAL (SIGLOS XIII-XV): ESTADO DE LA CUESTIÓN. DISCURSOS Y MOTIVACIONES
}

\author{
Alice TAVARES
}

Universidad Nova de Lisboa

\begin{abstract}
The case study presented in this article is an analysis of Portuguese literary manuscripts which deal with religious Jewish controversies during the Middle Ages (13th to the 15th centuries). These documents came down to us through the subsequent centuries and are available in the Libraries of Portugal. The article is intended to make known variegated documents of religious controversies over three centuries, while, at the same time, we shall draft a brief presentation of their authors, except for anonymous works. In the second part, we shall proceed with a definition of this particlar literary genre as well as analyze the characteristics and also the common features of the different works. In the end, we shall investigaate the discourses, motivations, and the different authors who have influenced the writing of these medieval controversies.
\end{abstract}

KEYWORDS: Middle Ages, Portugal, 13th-15th centuries, literature, manuscripts

RESUMEN. Este texto tiene por objeto de estudio los manuscritos portugueses de literatura de polémica judío-religiosa en la Edad Media (siglos XIII-XV) que llegaron hasta nuestros días y que se pueden encontrar en las Bibliotecas de Portugal. Se pretende, por un lado, dar a conocer las obras de controversia religiosa a lo largo de tres siglos, al mismo tiempo que, haremos una breve presentación de sus autores, excepto, de las obras anónimas. En la segunda parte, procederemos a la definición de este género literario y, posteriormente, analizaremos las características y los puntos en común entre las diferentes obras. Volcaremos nuestra atención hacía los discursos, las motivaciones y las distintos autores que han influido en la redacción de las obras de polémica medieval.

PALABRAS CLAVE: Edad Media, Portugal, siglos XIII-XV, literatura, lanuscritos

Este texto tiene como objeto de estudio las escasas obras de literatura de polémica judío-cristiana desarrolladas en Portugal durante la Edad Media entre los siglos XIII y XV. Este marco cronológico de amplio espectro-tres

* ALICE TAVARES (PhD 2014, University of Lisbon, Portugal) is Researcher in Medieval Studies at New University of Lisbon. Email: alice.tavares@gmail.com. 
siglos-corresponde a la primera obra de que tenemos conocimiento de este género literario-Summa Sermonum de Festivitatibus per anni circulum-de Fray Paio de Coimbra, fechada del siglo XIII hasta la conversión obligatoria al cristianismo y la expulsión definitiva de la comunidad judía y musulmana de Portugal (1497), decretada por D. Manuel I (1469-1521), en 5 de diciembre de 1496. Este procedimiento fue fundamental para la concretización del matrimonio de D. Manuel I (1469-1521) con la Infanta Doña Isabel (1470-1498), hija de los Reyes Católicos, D. Fernando de Aragón (14521516) y Doña Isabel (1451-1504) (Nogales 2017: 316). Consideramos estos últimos acontecimientos como marcos temporales cruciales en la política y en la sociedad medieval portuguesa, una vez que dieron lugar a una nueva realidad social y religiosa en la Península Ibérica: los cristianos nuevos.

A pesar de las determinaciones manuelinas, los casos de tensión e inestabilidad entre las comunidades, cristiana y judía, agudizados por los surtos de epidemias y por la llegada paulatina de familias judías y cristiano nuevas a Portugal expulsadas de Castilla, tuvieron continuidad, culminando posteriormente con la masacre de Lisboa, a primeros del siglo XVI, en 1506 (Mateus SM y Pinto PM 2007: 21-34).

Estos hechos estuvieron relacionados con una coyuntura más global, de carácter peninsular, con una larga tradición de persecuciones, conflictos e episodios de intolerancia ante la población judía. Los progroms de Sevilla (1391) fueron uno de los ejemplos que tuvieron más repercusión, generalizándose a los demás reinos ibéricos, en especial, Castilla y Aragón, teniendo como colofón, casi un siglo más tarde, la expulsión judía, por los Reyes Católicos, D. Fernando II de Aragón (1452-1516) y Doña Isabel I de Castilla (1451-1504), en 1492. Importa también recordar que, en un contexto un poco diferente, pero relacionado con la supervivencia de las minorías étnico-religiosas en la península, en este mismo año, se conquistó el último reino andalusí bajo el control nazarí: Granada.

No obstante, en Portugal, registramos un escenario distinto. Podemos decir que la convivencia entre cristianos y las minorías (judía y musulmana) fue relativamente pacífica a lo largo de la Edad Media hasta finales del siglo XIV. 1383-1385, para ser más precisos. Se trata de un momento particular, de cambio dinástico resultante de una coyuntura política de luchas intestinas por el poder regio, que contó con la participación de tropas castellanas, teniendo como consecuencia la ascensión al trono del Maestre de Avis, D. Juan I (1357-1433), en 1385. En éste contexto, se inauguró una nueva dinastía en Portugal, la dinastía de Avis. Con ella, las comunidades judías portuguesas se ven en una situación frágil, debido a revueltas por parte de las poblaciones. Estos comportamientos son igualmente una forma de manifestación en contra de las actuaciones de los judíos cortesanos, en especial de D. Juda Aben Menir y David Negro, validos y cortesanos de D. Fernando I 
(1345-1383), partidarios de su esposa, Doña Leonor Teles (1350-1386) y del Conde Andeiro (João Fernandes Andeiro, segundo Conde de Ourém, c.1320-1383), que representaban la causa castellana.

A lo largo del siglo XV hasta 1497, momento de la conversión y salida forzada de judíos, musulmanes y cristianos nuevos en diáspora hacía otros parajes, fueron parcos los momentos de inestabilidad y de conflicto entre los distintos grupos étnico-religiosos. Tenemos registro de episodios esporádicos de tensión entre las poblaciones cristiana y judía, tratándose, más bien, de criminalidad urbana de fácil control y resolución por parte de las autoridades regias y de levantamientos populares, excepto cuando se trató del caso residual del ataque a la judería grande de Lisboa (1482), a cuando de la conjura política en contra del rey D. Juan II (1455-1495). El objetivo consistío en afrontar al judío cortesano, Isaac Abravanel (1437-1508), cercano a la Casa de Braganza (Netanyahu 2013: 73-76). La reacción regia se circunscribió solamente en destrozar su casa, confiscar y repartir sus bienes, evaluados y concedidos al Hospital de Todos los Santos (en Lisboa) y al hijo de Moisés Latam (Tavares 1982: 419), Isaac Latam. Es decir, a Lourenço Vaz, judío recién convertido al cristianismo. No obstante, esta ocurrencia no tiene punto de comparación con los escenarios de violencia vividos en los demás reinos peninsulares.

Con esta breve contextualización, pretendemos también dar a conocer algunas de las razones de naturaleza política y social que estuvieron de algún modo relacionadas con el escaso desarrollo de este género literario de controversia religiosa en Portugal durante la Edad Media. Dentro de esta línea de pensamiento, podemos, en primer lugar, llamar la atención para la situación particular de las formas de vida y convivencia hasta cierto punto pacífica entre ambos grupos étnico-religiosos en tierras lusas. Además, hay que añadir el hecho particular de considerar las minorías étnico religiosas, como 'míos judíos' o 'mis musulmanes' por parte de los reyes portugueses desde el tiempo de la fundación de la monarquía, con D. Alfonso Henriques (1109-1185). Este hecho proporcionó una especie de estatuto especial a los judíos, siendo aceptados, respetados y tolerados, bien como sus modos de vida y principios religiosos. En cambio, estaban sujetos a una tributación especial.

Por otro lado, a esta cadena de acontecimientos, hay que acrecentar la ausencia de discusiones teológicas en suelo portugués o la ausencia de registros sobre ellas, como las Disputas de Barcelona (1263) y de Tortosa (1413), entabladas entre representantes o defensores de las tres religiones monoteístas (cristianismo, judaísmo e islamismo), contando con el incentivo regio o de señores (eclesiásticos o nobles). Estos debates sirvieron de base y de inspiración para el desarrollo de este tipo de obras de controversia religiosa 
que oponían cristianos, judíos y musulmanes, con el objetivo de hacer imperar la fe cristiana sobre los demás, incluso sobre los gentíos.

Los estudios sobre los manuscritos portogueses de controversia religiosa cuentan con alguna tradición en Portugal, desde las últimas décadas del siglo pasado. Encontramos especialmente investigaciones portuguesas y extranjeras de naturaleza filosófica, teológica, histórica y en el campo de la literatura. Es el caso del norte americano, John Gaston Tuthill, que dedicó su tesis doctoral (Tuthill 1982) al estudio de la obra sermonaria de fray Paio de Coimbra, fechada del siglo XIII. En el cómputo general, no encontramos en Portugal, análisis de carácter interdisciplinar sobre estas obras. Tampoco en las áreas de la historia del arte y codicología. Si atendemos a la historiografía, los escasos estudios sobre esta temática son dedicados, sobre todo a ediciones de algunas obras de polémica, como el caso del Libro de la Corte Imperial. Estas carecen de versiones más actualizadas y de investigaciones comparativas e interdisciplinares con la participación de estudiosos de distintos campos del conocimiento, sin olvidar la presencia de hebraístas y arabistas, con el fin de propiciar análisis más completos e intentar dar respuesta a muchas de las hipótesis que son fácilmente planteadas. Queda mucho por explicar, cotejar distintas fuentes e influencias de obras y autores extranjeros que sirvieron de base a la elaboración de los manuscritos portugueses. Otro fenómeno que queda también por aclarar son los mecanismos de circulación de estos códices. Son problemáticas que quedarán, de cierto modo en suspenso, puesto que esperan estudios posteriores.

El proyecto portugués de investigación-Hebrew Illumination in Portugal during the 15th century - fue un paso más para el conocimiento y valorización de las vivencias culturales y artísticas de la presencia judía en Portugal. Este incidió fundamentalmente en dos ejes temáticos neurálgicos: el libro y la miniatura. Gracias a esta iniciativa científica que tuvo como uno de los epílogos la celebración de una exposición de manuscritos en la Biblioteca Nacional de Portugal (Lisboa, 26 de febrero-15 de mayo de 2015), que contó con un catálogo acompañado por una serie de ensayos. Estos son dedicados a las distintas manifestaciones culturales y artísticas, sin olvidar la literatura y la ciencia asociadas a la comunidad judía, sobre todo con el libro y sus decoraciones. También proporcionaron, a modo de contextualización, un panorama global de las relaciones y vivencias de las comunidades judías en territorio portugués.

Organizamos este estudio en tres apartados. Daremos, en primer lugar, a conocer los manuscritos de literatura de polémica religiosa judío-cristiana en la Edad Media portuguesa que llegaron hasta los días de hoy. Haremos, al mismo tiempo, una breve presentación de sus autores, excepto, en el caso particular de las obras anónimas como la Corte Imperial. Aunque este estilo no sea originario de Portugal, tenemos conocimiento de la producción y 
circulación de este tipo de obras en el reino, incluso tenemos registro de un manuscrito con un texto de procedencia extranjera, del abad de Westminster, Gilberto Crispiano (ca. 1046-1117), en el cenobio de Cister, en Alcobaça. Sobre ellas, dejaremos algunas indicaciones, puesto que han llegado a Portugal y han suscitado interés en el seno de la comunidad monástica de Alcobaça. En segundo lugar, enfocaremos las características principales de este género literario, los discursos, las motivaciones y las influencias de otros autores o manuscritos, sobre todo extranjeros.

\section{Manuscritos portugueses de literatura de polémica religiosa}

Como ya hemos dicho, se trata de un estilo poco cultivado en Portugal, aunque tengamos conocimiento de la existencia de algunos manuscritos producidos en el reino. Estos se pueden encontrar actualmente en los acervos archivísticos y bibliotecarios portugueses. Empecemos con la Summa Sermonum de Festivitatibus per anni circulum del monje dominicano de Coimbra, fray Paio de Coimbra (Pelágio Parvo), contemporáneo de San Antonio de Lisboa (1191-1231), redactada en el siglo XIII. Esta obra consiste en la recopilación de 407 sermones 'casi todos panegíricos de santos' (Martins 1973: 345) en latín, llevada a cabo por el monje de Císter de Alcobaça, Domenicus Petri-Domingos Pires o Peres-en 1250. Actualmente, este legado se encuentra también en la Biblioteca Nacional de Portugal (Lisboa), en el expolio de los manuscritos Alcobacenses. Su estructura corresponde al calendario litúrgico, acoplando los sermones en función de las festividades religiosas. Es decir, los sermones deberían empezar por el Adviento, más en concreto a partir del 30 de noviembre con la celebración dedicada a San Andrés. Por otra parte, estos deberían acabar en el día 25 de noviembre con la festividad a Santa Caterina (Dias 1984: 384; Tavares 2010: 179).

Del siglo XIV tenemos noticia de tres obras. Empecemos con Colírio da Fé (Collyrium fidei adversus haereses) de fray Álvaro Pais Gomes de Chariño (1275/80-1349), redactado entre 1330 y 1340 (Calafate 1999: 221-251). Se trata de una obra organizada en seis partes, correspondiendo cada una a principios doctrinales. Cada artículo es utilizado para exponer una herejía o un error (Tavares 2010: 182). Además, sus intentos en defensa del cristianismo van más allá de la doctrina, inmiscuyéndose en los comportamientos y vivencias entabladas entre personas de distintas religiones como las relaciones íntimas o matrimonios entre cristianos y moros o judíos (Tavares 2010: 183). Pretendía de esta forma controlar los aspectos del día a día entre las comunidades, reglamentando y definiendo los comportamientos más adecuados para los cristianos (Álvaro Pais 1956: 186-189). Fue en este sentido que el autor procedió a la identificación y al inventario de las herejías existentes en el seno de la Cristiandad para que sirvieran de "colirio" a los infieles. O sea, el colirio debería funcionar como una especie de tratamien- 
to, de aplicación tópica para curar la ceguera (Carvalho 2001: 44). Según él, la iglesia tiene un papel importante en contradecir y hacer frente a las herejías.

De autor anónimo, disponemos el Tratado Theologico em que se comprova a verdade da Religião a Jesu Cristo, a falsidade da Lei dos judeos e a vinda do Messias, que pertenece a la Colección Iluminados, igualmente de la Biblioteca Nacional de Portugal (BNP, Coleção de Iluminados, n⿳047), en Lisboa. Anteriormente, este manuscrito perteneció a fray Manuel del Cenáculo, regalándolo a la Real Biblioteca Pública de la Corte, en 1791 (Moita 2015: 150). Poco sabemos de esta obra que llegó a nosotros, llevándonos a plantear muchas hipótesis. Por ejemplo, su autor y sus orígenes. Posiblemente, se trate de una obra de las primeras décadas del siglo XIV, correspondiente al reinado de D. Dinis (1261-1325) (Moita 2015: 150). Su estructura es semejante al manuscrito anterior, pues se divide en doce apartados. Es decir, cada tópico corresponde a un artículo de la fe cristiana que es explicado por un apóstol para probar la superioridad del cristianismo en relación a las demás religiones monoteístas. Este tratado obedece a unas características distintas, una vez que, según las palabras de Joaquim Assunção Ferreira (Ferreira 2006: 351-353) y de José Antunes (Antunes 1996: 338) estamos delante de una versión en portugués de uno de los libros fundamentales de polémica antijudía hispánica: el Libro de las Tres Creencias, del judío converso Alfonso Valladolid (rabino Abner de Burgos, ca. 1270-1347) (Moita 2015: 149-150; Cepeda 1986: 217-224). Esta versión, en comparación con la obra castellana, le faltan algunas partes. Son ejemplo el 'primer folio y la última parte, compuesta por los capítulos referentes a los Sacramentos y a la Virgen María' (Tavares 2010: 180; Antunes 1996: 346).

Espelho dos Hebreus, de Fray João de Alcobaça, es una obra formada por dos manuscritos. Estos pertenecieron igualmente al expolio del monasterio cisterciense de Alcobaça, encontrándose actualmente en el depósito de la Biblioteca Nacional de Portugal (Lisboa). El primer manuscrito, conocido por códice 236, es del año 1333, mientras que, el segundo, designado de códice 270, es posterior, remontando al año de 1345. Estos manuscritos han tenido como inspiración la Disputa de Barcelona, en julio de 1263 (Limor 2010: 58-59), celebrada en la presencia del rey de Aragón (Jaime I, 12131276), que contó con la participación de Moisés ben Nahman (Nahmánides o Bonastruc ça Porta, en catalán), rabino de Gerona y del monje dominico, Pablo Cristiano (Pau Christiá), judío converso, que contó con el apoyo de miembros de las órdenes mendicantes (Beinart 1992: 107-109).

Ambos manuscritos están redactados en latín, si bien podamos encontrar algunos pasajes en hebreo, en 'caracteres latinos' (Antunes 1996: 374; Tavares 2015: 144). A parte destas huellas, registramos en los dos códices otro punto en común: la presencia de una especie de gramática de las lenguas 
caldaica y hebraica, también en caracteres latinos, Ars brevissima scriturae Hebraicae et Chaldaeae Latinis Litteris cognoscendae, con la finalidad de instruir los lectores y potenciales interesados en las pregaciones y discusiones teológicas en defensa del cristianismo. Estamos, por lo tanto, ante una característica peculiar que sólo encontramos en estos manuscritos de Fray João de Alcobaça que además de tener una función teológica, tienen una finalidad pedagógica. Este hecho demuestra un claro conocimiento de las lenguas orientales que circulaban en el seno de la comunidad monástica portuguesa y que era difundido a través de este tipo de obras.

De particular interés disponemos de una copia de la Corte Imperial, más conocida por $O$ Livro da Corte Imperial, pues se trata de una obra con características pioneras en Portugal, debido al diálogo entablado en portugués (Tavares 2017: 169), entre las distintas personajes con matices teatrales, como veremos en el siguiente apartado. Su fecha es incierta, poco consensual, pudiéndose fijar entre fines del siglo XIV o a primeros del siglo XV (Gomes 1981: 132). Se trata de una de las interrogantes de esta obra. Sus orígenes, bien como su autoría son otros puntos de discusión que han permitido plantear distintas hipótesis.

Pese a esto, disponemos de algunas informaciones sobre el único manuscrito fechado del siglo XVIII, que se encuentra en la Biblioteca Pública Municipal de Oporto (Portugal). Este consiste en una copia apógrafa (Díaz Marcilla 2012: 82) encontrada en un manuscrito 'membranáceo de letra gótica', que perteneció al criado del Duque de Braganza, Afonso Vasques de Calvos, morador de Beja (Alentejo, Portugal). Es muy probable que este fuera también el autor del libro. Es la hipótesis planteada por Gouveia Neves (Neves 1971: 150-153). Pero, antes este manuscrito tuvo otros propietarios. El monasterio de Santa Cruz, en Coimbra (Portugal), fue unos de los primeros en poseer la referida obra. Corte Imperial circuló, más tarde, por otras manos, haciendo parte de la biblioteca del rey D. Duarte (1391-1438). Otra hipótesis que podemos plantear es la supuesta pertenecía de otro ejemplar entre los bienes de la infanta D. Beatriz (1430-1506), nuera de D. Duarte (1391-1438) y duquesa de Viseu. El periplo de este manuscrito termina en el monasterio de 'San Antonio de Beja por Antón de Oliveira a través del portero Luis d'Atouguia de Ruy Paes, el 21 de diciembre de 1507' (Tavares 2010: 185). Este libro cuenta actualmente con dos trabajos de edición de: J. M. da Cruz Pontes (Pontes 1957: 1-478) y Adelino Cardoso (Cardoso 2000).

Horologium Fidei o 'Relógio da Fé' es outro ejemplar de la primera mitad del siglo XV, cuyo autor es un fraile franciscano de Évora (Alentejo), André do Prado. Se trata de una obra encargada por el Infante D. Enrique (13941460), Duque de Viseu y Señor de Covilhã, posiblemente, cuando Prado estuvo en Portugal. El local de redacción de esta obra acarrea algunas du- 
das, si fue en Portugal o en Italia. Esta duda fue disipada, situando el origen de la obra en tierras portuguesas (Nascimento 1994: 87). Posteriormente, fue llevado para Italia, quedándose en la Biblioteca de la Curia Pontificia, Roma (Tavares 2010: 188). Con algunas características semejantes a la Corte Imperial, dedicaremos nuestra atención de manera más detenida en el último apartado.

Poco se sabe del manuscrito Adjutorium Fidei (Ajuda da Fé) igualmente del siglo XV, que se encuentra conservado en el acervo del Colegio de Évora de los Padres Jesuitas, en Alentejo (Kayserling 1971: 75). Sobre su autor Maestre Antonio, tenemos conocimiento que fue un judío converso, ahijado del rey portugués-D. Juan II (1455-1495)—cuando aceptó convertirse al cristianismo (Tavares 2010: 191). Además de físico y de ejercer medicina, se dedicó a polemizar en contra de sus correligionarios. Seguidor de Jerónimo de Santa Fé (Yehosua ha-Lorki), también médico converso del reino de Aragón y partícipe de en la Disputa de Tortosa (1413), Maestro Antonio contribuyó con su obra para polemizar y oponer las religiones cristiana y judía (Tavares 2015: 96).

Saliendo de esta línea de raciocinio con el fin de enumerar los pocos manuscritos de controversia, centramos nuestra atención en un caso particular que ocurrió en Portugal, en el reinado de D. Alfonso V (1432-1481). Se trata de los sermones de Maestre Paulo de Braga (Portugal), predicados en contra de la minoría judía de su ciudad natal. Tenemos noticias de su sermonaria y de las consecuencias que han tenido en la población de Braga, a través de fuentes indirectas, pues no hay registros de sus predicaciones. Para ser más precisos, de dos epístolas regias de D. Afonso V (1432-1481) dirigidas al Deán y al Cabildo de la Catedral de referida ciudad, conservadas en el Archivo Distrital de Braga (Moreno 1976: 6; Tavares 2015: 97). Gracias a estos documentos podemos confirmar las quejas de la población judía e intuir los sentimientos antijudíos y las exigencias del fraile en querer cambiar sus comportamientos religiosos y modos de vida, con la intención de mantenerla apartada de los demás grupos sociales de Braga (Moreno 1976: 12; Tavares 1982: 437). Las predicaciones de Maestre Pablo nos permiten plantear una serie de cuestiones. Debemos tener en cuenta la premisa de que en Braga no hubo sospechas de conflictos y rasgos de violencia resultantes del enfrentamiento entre ambas comunidades religiosas, aunque tengamos la noción de las quejas emprendidas por parte de los judíos que supuestamente se sentirían amenazados. Lo mismo podemos decir de la actitud proteccionista del soberano al colocarse al lado de la minoría judía, defendiéndola (Moreno 1976: 8; Tavares 2010. 191). Planteamos esta situación, porque si comparamos el caso de Braga con otras ciudades del reino, como Lisboa o Oporto, que fueron escenario de comportamientos de violencia y escaramuzas (mismo que se traten de casos puntuales) por parte de 
la mayoría cristiana contra los judíos, no tenemos noticia de este tipo de hechos en Braga.

Por otra parte, no debemos olvidar la existencia de un manuscrito extranjero que llegó a Portugal, que fue copiado en el cenobio de Alcobaça. Perteneció al expolio de la congregación de Cister, depositado hoy en día en la Biblioteca Nacional del referido país, en Lisboa. Dialogus contra Judeos (Incipit liber petrus alphonsi ex iudeo christianissimi f. 2-123) es un caso semejante a Adjutorium Fidei, pues fue escrito por un judío converso-Pedro Alfonso-al igual que su congénere portugués, Maestro Antonio, con objetivos análogos de polemizar contra la religiones profesadas por judíos y musulmanes. Sobre Pedro Alfonso tenemos conocimiento de su bautizo en Huesca (Comunidad Autónoma de Aragón, España), en 1106. Esta ceremonia contó con la presencia de su padrino, el rey D. Alfonso I de Aragón (1073-1134) (Miranda 2015: 151). Este autor estuvo en Inglaterra, tal como Gilberto Crispiano (ca. 1046-1117). Este último, abad de Westminster. que redactó la obra, Disputatio Judaei et Christiani (Incipit epistola gisleberti abbatis f. 123-147). En las palabras de Adelaide Miranda, este texto es diferente, debido a su registro 'tolerante como trata o tema, na tradição de Santo Anselmo' (Miranda 2015: $151)$.

\section{Discursos, motivaciones e influencias}

Puesto esto, la literatura de polémica o de controversia religiosa es un estilo que consiste en la defensa y valorización del cristianismo en perjuicio de las demás religiones monoteístas y de otras manifestaciones religiosas ante la religión cristiana. El objetivo neurálgico de este tipo de textos reside en la conversión de los judíos, musulmanes, gentíos o de otras comunidades al cristianismo, demostrando que estes se encuentran equivocados en seguir sus preceptos, mientras que, por otro lado hay la preocupación de enseñarles la doctrina cristiana. Subsiste la intención de evangelizar y difundir la fe cristiana a los pueblos, haciéndoles aceptar el cristianismo, al mismo tiempo que se deberían combatir las herejías, por lo menos de forma pacífica, a través del diálogo. Por ejemplo, es la vía propuesta en el Libro de la Corte Imperial, con base en las influencias de conversión de Ramón Llull (ca 12321315), al proporcionar un debate ecuménico donde todos los representantes de las religiones monoteístas, sin olvidar los gentíos y al obispo griego, estaban presentes en un escenario muy propio, la Corte imperial, presidida por Cristo, como si fuera un emperador celestial (Tavares 2017: 161). Es decir, la conversión al cristianismo se debería hacer a través de la palabra, del diálogo, en vez de la guerra (Higuera 2001: 86), pues era más eficiente que por vía de la fuerza.

Por otro lado, hay el problema del cristiano nuevo. Esta nueva figura socio-religiosa, resultante de las conversiones forzadas de judíos y moros (So- 
yer 2008: 33-62) determinadas por los poderes regios (en España por los Reyes Católicos y, en Portugal, por el monarca D. Manuel I), era susceptible a desconfianzas y animosidades por parte de la mayoría cristiana, bien como por parte de la comunidad judía. Por otras palabras, ni todos los conversos practicaban de forma fiel y convicta los principios cristianos (López 1992: 39), aunque fueran bautizados. Eran, por lo tanto, más vulnerables a prácticas criptojudías (es decir, eran judíos convertidos al cristianismo, pero que seguían profesando la religión judía de forma secreta) y judaizantes. En este último caso, estamos delante de cristianos nuevos que no solo practican el judaísmo, sino también iniciaban a otros (Mateus y Pinto 2007: 68). Este hecho está relacionado con la adopción forzada de los principios cristianos, haciendo de ellos, en muchos casos, un mecanismo de supervivencia para disimular las creencias judías (Tavares 2015: 94). En este sentido, el segundo objetivo de las obras de controversia, sobre todo a partir de finales del siglo XV, consiste en la atención especial dedicada a los conversos, pues constituyeron un problema socioreligioso para los monarcas peninsulares. Se persistía la finalidad de garantizar la conversión y el cumplimiento de los principios cristianos entre los conversos.

Las obras de polémica religiosa judío-cristiana tienen temáticas de debate análogas. Uno de los ejes centrales es la discusión de la doctrina cristiana, el Credo o El Símbolo de los Apóstoles. Es decir, la existencia de un Dios único, la Santísima Trinidad; el nacimiento de Jesucristo, el pecado original, inherente a todo el ser humano; la Encarnación, entre otros principios básicos de la fe cristiana. Por ejemplo, son la base del diálogo entre André do Prado, que asumió el papel de consejero, y del Infante D. Henrique (13941460), Duque de Viseu y Señor de Covilhã, con el sentido de dar a conocer y reflexionar sobre las herejías. El diálogo de estas dos personajes del siglo $\mathrm{XV}$, en la obra Horologium Fidei, se encaja en los puntos de controversia y de debate sobre la importancia y origen del Credo en los concilios (Pisa, Basilea, Ferrara y Florencia) y dentro del círculo de humanistas como Lorenzo Valla)' (Tavares 2010: 188).

En los sermones y en los diálogos podemos encontrar, además, otras líneas de debate, entre las cuales el Sacramento de la Eucaristía y el fenómeno de la Transubstanciación. Estos fenómenos no solían ser de fácil comprensión para las comunidades judía y musulmana.

La llegada del Mesías es un tema muy particular que solo lo vemos en la discusión entablada entre los rabinos y el personaje-Iglesia Imperial—, en la Corte Imperial. Estamos delante de un punto sensible para la comunidad judía, pues la representante cristiana intentó probar que Cristo es el Mesías, el anhelado Redentor para libertar el pueblo judío (Tavares 2015: 96) ya que, en el Antiguo Testamento, en el Libro del Génesis 49:10, se encuentra debidamente especificado el momento y el lugar de su nacimiento. Las ar- 
gumentaciones de los judíos tuvieron el objetivo de demonstrar las amarguras y las persecuciones sufridas por ellos como, por ejemplo el cautiverio de Babilonia, y la necesidad de buscar nuevos lugares, dispersándose por el mundo (Cardoso 2000: 176-177).

Todas estas obras obedecen a distintas formas de redacción. Algunos manuscritos resultan de recopilaciones de sermones, cuya aplicación iba más allá de los espacios monásticos (Dias 1984: 382). El objetivo asentaba en direccionar los sermones y sus contenidos a todas las poblaciones en general, pues era necesario identificar y combatir las herejías. La sermonaria es una técnica que se inserta en un contexto de refuerzo de la predicación popular, relacionada con el desarrollo de las órdenes mendicantes, dominicos y franciscanos, y con una nueva dinámica de la vida urbana, con el renacimiento de las ciudades, sobre todo, a partir del siglo XIII. Tenemos el caso de la sermonaria de Fray Paio de Coimbra, redactada en latín, con la intención de luchar contra los heréticos típicos de su época, empezando por los cátaros o albigenses (Bolton 1983: 70-71). Además de estos grupos heréticos había la necesidad de incluir los musulmanes y los judíos. Esta sermonaria, en resumen, funcionaba como una 'especie de manual práctico de cómo hacer sermones’ (Tavares 2010: 179).

El diálogo, es decir la altercatio, es otra técnica de discurso empleada en las obras de controversia a partir del siglo XIV. Por ejemplo, en el Libro de la Corte Imperial, se pretende incentivar la discusión interreligiosa entre los varios personajes con asiento en la Corte Imperial, para ser más precisos, en la Corte de Cristo. A este espacio cortesano confluyeron una serie de personajes, entre las cuales representantes de las tres religiones monoteístas (cristianismo, judaísmo e islamismo), un obispo griego y los gentíos, más conocidos por ateos. Como ya hemos dicho anteriormente, cabía a Cristo presidir la Corte, mientras que su esposa para toda la eternidad-la Iglesia Triunfante-estaba sentada a su derecha. A la corte imperial, acudió la Iglesia Militante, una figura femenina proveniente de Oriente, con un carácter misionario y proselitista, a la cual estaba encargada de direccionar el debate teológico y filosófico entre todos los elementos de las otras religiones (Tavares 2017: 167-168). El objetivo era propiciar un debate ecuménico, donde se exponían las herejías de los otros pueblos (judíos, por ejemplo), contando con la presencia de distintas ideas teológicas entre los diferentes líderes religiosos. Esta misión comportaba de igual modo la divulgación de la palabra de Dios a todas las personas presentes, haciéndolas creer que estaban equivocadas. Este es uno de los puntos de confluencia con las ideas de Ramón Llull (ca 1232-1315), que asentaban en llevar la fe cristiana, con base en el debate, a las poblaciones musulmanas de la Península Ibérica y del Norte de África (Tavares 2017: 168). 
Veamos otros ejemplos. En la obra 'Relógio da Fé' o Horologium Fidei, el debate se establece entre dos personajes: el autor, André do Prado y el Infante D. Henrique (Tavares 2015: 95). La base fundamental de esta conversación reside en la discusión del Símbolo de los Apóstoles, El Credo (Carvalho 2001: 13). Por otras palabras, la idea consistía en dar a conocer las discusiones del origen y de la importancia del 'Credo en los concilios (Pisa, Basilea, Ferrara, Florencia) y dentro del círculo de los humanistas (como Lorenzo Valla) de la primera mitad del siglo XV' (Tavares 2010: 188; Carvalho 2001: 13). Ya en la obra-Adjutorium Fidei (Ajuda da Fé)—el diálogo es llevado a cabo también entre dos figuras, un judío y el propio Maestro Antonio, con el fin de contestar los argumentos de su interlocutor, en beneficio de la doctrina cristiana (Tavares 2010: 191).

Todos estos casos tienen en común la preocupación no solo de debatir y dar a conocer los dogmas cristianos, sino también de evangelizar y de llevar la fe cristiana a otros pueblos. El diálogo permite expandir el cristianismo a través de la paz, sin proceder a la guerra y a la conversión forzada. Estas formas de violencia sólo llevaban a revueltas, a situaciones teológicas confusas y duales entre las personas. En las obras donde se practica el diálogo, todos los personajes son escuchados y además, exponen sus principios religiosos de forma clara y respetuosa, sin altercados, propiciando un entorno de paz y tolerancia. Es una manera de exponer las herejías, simplificar y facilitar la conversión al cristianismo.

Para facilitar esta tarea de evangelización, con el sentido de llevar la doctrina cristiana a todos los pueblos, registramos el uso de la lengua vernácula, el portugués, ya en la Corte Imperial, desplazando el latín. Las obras de polémica religiosa identificadas a partir del siglo XIV son redactadas en portugués, puesto que el idioma nativo de las propias comunidades funcionaba como un instrumento primordial en el trabajo de llevar la fe cristiana a todas partes, facilitando la comprensión de las predicaciones por los misioneros y demás eclesiásticos. El latín ni siempre era una lengua asequible a la mayoría de las gentes. Estamos, por lo tanto, delante de un mecanismo esencial en el combate en contra las herejías, como el judaísmo. De este modo, nos acercamos a las tareas promovidas por las órdenes mendicantes en la transmisión de la palabra de Dios.

El conocimiento de las lenguas orientales (árabe, hebraico y caldaico) es también fundamental para conocer las otras religiones y las costumbres de los pueblos, con más profundidad, superando las barreras de comunicación entre las personas. Por ejemplo, una de las formas encontrada por Fray João de Alcobaça fue la publicación de una gramática-Ars brevissima scriturae Hebraicae et Chaldaeae Latinis Litteris cognoscendae-en caracteres latinos, de las lenguas hebraica y caldaica en su Speculum Hebraeorum o Speculum disputationis contra Hebraeos. El objetivo de este fraile consistía en formar 
otros controversistas para que tuvieran un conocimiento más detallista de los principios y de los modos de vida judíos e islámicos. Este tipo de gramáticas era utilizado como un instrumento de trabajo esencial para identificar y contestar las herejías, rebatiéndolas en los debates polemistas, a favor del cristianismo. Esta iniciativa estaba de acuerdo con los intereses del Papado, en especial de Clemente V (1305-1314) de incentivar los estudios de las lenguas y culturas orientales (Tavares 2015: 144). Asimismo, el Tratado Theologico em que se comprova a verdade da Religião a Jesu Cristo, a falsidade da Lei dos judeos e a vinda do Messias es una de las pruebas de que los autores eran conocedores no sólo del latín, sino también del hebraico y árabe. Este hecho lo podemos observar en las traducciones latinas y en portugués de las transcripciones de la Biblia judía en hebraico para el portugués y latín (Moita 2015: 149).

Cuando analizamos las obras de controversia objeto de estudio, nos percatamos que sus autores tenían un conocimiento detallista de los libros sagrados de los musulmanes (Corán e Hadiths) y de los judíos para poder refutar con más vehemencia los principios del islamismo y judaísmo. Tenemos el ejemplo de la Torah y del Talmud, que reside en el registro de discusiones rabínicas, organizado en dos partes: la Mishna, código de tradiciones orales y la Guemara, comentario del Mishna (Garcia 2000: 60, Tavares 2017: 172). El Targum, que consiste en traducciones y comentarios en arameo de la Bíblia hebraica y la Midrash, colección de enseñanzas exegéticas sobre la Torah, son otros libros judíos que sirvieron de suporte a los autores controversistas (Tavares 2017: 172).

En los manuscritos del Speculum Hebraeorum ou Speculum disputationis contra Hebraeos de Fray João de Alcobaça se pueden encontrar temáticas relativas al Zohar, libro central de la Cabala. Son ellas el emanacionismo, el panteísmo y la preexistencia de las almas (Tavares 2010: 184).

Otros recursos y argumentos son utilizados por los autores polemistas basados en ejemplos Bíblicos, más en concreto, del Antiguo Testamento (Génesis, Salmos, por ejemplo) para hacer predominar las doctrinas del cristianismo en los debates en contra de los judíos. La idea consistía en confundir los representantes judíos por las 'autoridades por eles admitidas' (Nascimento 1994: 94). O sea, el Antiguo Testamento era del conocimiento mutuo de los cristianos y judíos, aunque hagan interpretaciones diferentes (Antunes 1996: 375). Los textos de los Santos Padres no fueron, por lo demás, olvidados como ocurre en el Sermonario, Summa Sermonum de Festivitatibus per anni circulum, de fray Paio de Coimbra (Tavares 2010: 179-180) y en el Horologium Fidei, de André do Padro.

Los autores de polémica judío religiosa se han inspirado y basado sus ideas en obras de otros filósofos y pensadores relacionados, sobre todo con las órdenes mendicantes, puesto que estas congregaciones religiosas eran 
detentoras de sentimientos catequéticos, con el fin de dar a conocer y llevar la fe cristiana a todos los pueblos considerados infieles. Empecemos con Ramón Llull (ca 1232-1315), cuyos textos sirvieron de suporte para rebatir los principios de los moros y judíos, como, por ejemplo, en las obras anónimas, Tratado Theologico em que se comprova a verdade da Religião a Jesu Cristo, a falsidade da Lei dos judeos e a vinda do Messias y de la Corte Imperial, en el debate entre los rabinos, el alfaquí y la Iglesia Militante. Las obras del filósofo franciscano mallorquín más utilizadas son la Disputatio Raymundi Christiani et Hamar Saraceni, Los tres savis o Ars Magna y el Libre del gentil.

Asimismo, los autores de este género literario utilizaron obras de otros pensadores contemporáneos a Ramón Llull (ca 1232-1315), entre las cuales el Pugio Fidei y Capistrum Judaeorum, del dominico catalán Raimundo Martí (ca 1220-1284), hebraísta y arabista, para contestar los judíos. Es el caso del Livro da Corte Imperial (Pontes 2006: 239). La situación es semejante al francés, Nicolás de Lira (1270-1349), monje franciscano de ascendencia judía (Pontes 2006: 230-231).

El poema, De Vetula, supuestamente atribuido a Ovidio, fue otro texto que sirvió de suporte a la retórica de la Iglesia Militante en la Corte Imperial. Otros autores clásicos y profanos, como Aristóteles, han servido, de igual modo, de referencia al autor anónimo de la referida obra. Este hecho demuestra claramente la erudición de los personajes que participan en la Corte de Cristo.

\section{Conclusión}

Al contrario de los demás reinos de la Península Ibérica, la literatura de controversia judío-cristiana en Portugal tuvo poco impacto. En las palabras de Maria José Ferro Tavares, son apuntadas dos causas: la ausencia de registros sobre este tipo de fenómenos de discusión filosófica y teológica que oponían cristianos y judíos en defensa de sus principios religiosos, como ocurrió en Barcelona (1263) y Tortosa (1413). Hay que subrayar como otra causa la poca importancia y la posibilidad de debates amistosos entre representantes de comunidades étnico-religiosas diferentes (Tavares 1982: 439). Sí es así, hay que tener en cuenta la suposición de que hubo discusiones teológicas en Portugal, aunque tengamos acceso a obras de polémica originarias de Portugal y a otros manuscritos de autores extranjeros producidos en Inglaterra y España, que llegaron a nosotros desde la Edad Media. Sin embargo, la mayoría de estas obras no acompañan los acontecimientos de intolerancia y rebelión en contra de la comunidad judía como pasó en los demás reinos peninsulares. Si bien, estos hechos se empezaron a registrarse a partir del siglo XIV, de forma residual hasta la situación límite tras la expulsión de los judíos por los Reyes Católicos, en 1492 y, años más tarde, por el rey D. Manuel I, en 1497. Con esto todo, no sabemos el impacto y las conse- 
cuencias que las obras de polémica han tenido en la sociedad portuguesa, con la excepción de los sermones de Maestro Paulo de Braga, pues tenemos conocimiento de su supuesta existencia a través de fuentes indirectas.

La literatura de polémica de controversia judío-religiosa en Portugal es todavía un desafío para el investigador, pues se trata de una temática llena de interrogantes y de hipóteses que no están aún aclaradas. Además, hay la necesidad de destacar que este género literario requiere un estudio más riguroso y detallista, sobre todo en una perspectiva interdisciplinar, contando con la colaboración de la historia, historia del arte, codicología, teología, filosofía, entre otros campos del conocimiento. Es también fundamental averiguar los mecanismos de circulación de manuscritos de controversia religiosa, de ideas, de influencias de otros autores como, por ejemplo Ramón Llull o Raimundo Martí, y el impacto que tuvieron, sobre todo en Portugal.

\section{Bibliografía}

Antunes J (1996) A cultura erudita portuguesa nos séculos XIII e XIV (juristas e teólogos). PhD Thesis, Universidad de Coimbra, Portugal.

Beinart H (1992) Los judios en España. Madrid: Editorial MAPFRE.

Bolton B (1983) A reforma na Idade Média. Séc. XIII. Lisboa: Edições 70.

Calafate P (1999) Frei Álvaro Pais. In Calafate P (ed) História do Pensamento Filosófico Português. Lisboa: Caminho, pp. 221-251.

(1910) Collecção de manuscritos inéditos agora dados à Estampa. O Livro da Corte Imperial. Porto: Real Bibliotheca Pública Municipal do Porto.

Cardoso AA (2000) Corte Enperial. Aveiro: Universidade de Aveiro.

Carvalho MS (2001) Estudos sobre Álvaro Pais e outros franciscanos (séculos XIII$X V)$. Lisboa: Imprensa Nacional Casa da Moeda.

Cepeda IV (1986) Uma versão portuguesa do Libro de las tres creencias. Revista da Biblioteca Nacional 2(I): 217-224.

Dias GAC (1984) Os sermões de Fr. Paio de Coimbra e o Antigo Testamento. In Actas do II Encontro sobre História Dominicana. Mesa Redonda sobe Fr. Paio $e$ os seus sermões. Porto: Arquivo Histórico Dominicano Português, pp. 347-363.

Díaz FJ (2012) Estudio sobre la bibliografía del lulismo de Portugal en los Siglos XIV y XV. Studia Lulliana 52: 81-94.

Ferreira JA (2006) Estatuto jurídico dos judeus e mouros na Idade Média (Luzes e sombras na convivência entre as três religiões). Lisboa: Universidade Católica Editora.

Garcia MA (2000) Os judeus de Belmonte. Os caminhos da memória. Lisboa: Instituto de Sociologia e Etnologia das Religiões. Universidade Nova de Lisboa. 
Gomes P (1981) História da Filosofia Portuguesa. A filosofia hebraica-portuguesa. Porto: Lello \& Irmão-Editores.

Higuera J (2001) Honor y dialética (Sobre la representación caballeresca de Ramón Llull en el Breviculum de Tomás de Myésier). In Fidora A y Higuera J (eds) Ramón Llull. Caballero de la Fe. El Arte Luliana y su proyección en la Edad Media. Pamplona: Servicio de Publicaciones de la Universidad de Navarra, pp. 81-106.

Limor O (2010) Polemial varieties: religious disputations in 13th Century Spain. Iberia Judaica 2(*): 55-79.

López N (1992) Teología de controversia sobre judíos y judaizantes españoles del siglo XV. Ambientación y principales escrito. Anuario de Historia de la Iglesia $1(*)$ : 32-70.

Martins M (1973) O sermonario de Frei Paio de Coimbra do Cód. Alc. 5/CXXX. Didaskalia 3(*): 337-361.

Mateus SB y Pinto PM (2007a) Lisboa, 19 de abril de 1506. O massacre dos judeus. Lisboa: Aletheia Editores.

Mateus SB y Pinto PM (2015b) O quattrocento ibérico, ou o desenvolvimento da impossibilidade do convívio entre Judeus e Cristãos. In Afonso LU y Pinto PM (eds) O livro e as interações culturais judaico-cristãs em Portugal no final da Idade Média. Lisboa: Cátedra de Estudos Sefarditas «Alberto Benveniste» de la Universidad de Lisboa, pp. 99-117.

Miranda A (2015) 21. Pedro Afonso, Dialogus contra Judeos (ff.1-124); Gilberto Crispiano, Disputatio Judei cum Christiano (ff. 124-147). In Afonso LU y Miranda A (eds) O livro e a iluminura judaica em Portugal no final da Idade Média. Lisboa: Biblioteca Nacional de Portugal, pp. 151152.

Moita T (2015) 20. Libro de las tres creencias. In Afonso LU y Miranda A (eds) O livro e a iluminura judaica em Portugal no final da Idade Média. Lisboa: Biblioteca Nacional de Portugal, pp. 149-150.

Moreno HB (1976a) As pregações de Mestre Paulo contra os judeus bracarenses nos fins do século XV. Revista Bracara Augusta 30(*): 3-12.

Moreno HB (1986b) Novos elementos relativos a Mestre Paulo, pregador do século XV, contra os judeus bracarenses. Revista Bracara Augusta $32(*): 5-12$.

Nascimento AA (1994a) O diálogo de André do Prado com o Infante D. Henrique: o Horologium fidei. Viseu: Edição da Câmara Municipal de Viseu.

Nascimento AA (1994b) O Diálogo de André do Prado com o Infante D. Henrique: o Horologium Fidei. Mare Liberum. Revista de História dos Mares $7(*)$ : $85-104$.

Netanyahu B (2013) Dom Isaac Abravanel. Estadista e Filósofo. Coimbra: Tenacitas. 
Neves AJG (1971) A Corte Imperial. Um valioso manuscrito do séc. XVIII, da Biblioteca Municipal do Porto. «Boletim Cultural» da Câmara Municipal do Porto 34(1-2): 5-8.

Nogales D (2017) Em torno dos casamentos de D. Manuel I com as infantas de Castela D. Isabel e D. Maria. In Rodrigues ANSA, Silva MS y Faria AL (eds) Casamentos da família real portuguesa. Diplomacia e ceremonial, Lisboa: Círculo de Leitores, pp. 313-349.

Pais A (1956) Collyrium fidei adversus haereses. In Meneses MP (trans) Colírio da fé contra as heresias. Lisboa: Centro de Estudos de Psicologia e de História da Filosofia anexo à Faculdade de Letras.

Pontes JMC (1957a) Estudos para uma edição crítica do Livro da Corte Enperial. Biblos 32(*): 1-478.

Pontes JMC (2006b) Apostilas para a edição crítica do Livro da Corte Enperial. Revista Humanitas 58(*): 229-252.

Soyer F (2007a) The persecution of the Jews and Muslims of Portugal: King Manuel I and the End of Religious Tolerance (1496-7). Leiden/Boston: Brill.

Soyer F (2008b) King Manuel I and the expulsion of the Castilian Conversos and Muslims from Portugal in 1497: new perspectives. Cadernos de Estudos Sefarditas 8(*): 33-62.

Tavares A (2010a) La literatura de polémica religiosa judeocristiana en Portugal antes de la expulsión, en 1497. Iberia Judaica. La polémica judeocristiana en Hispania. The Jewish-Christian Controversy in Hispania 2(*): 177-192.

Tavares A (2015b) A literatura de polémica judaico-cristã em Portugal no século XV. In Afonso LU y Miranda A (eds) O livro e a iluminura judaica em Portugal no final da Idade Média. Lisboa: Biblioteca Nacional de Portugal, pp. 93-98.

Tavares A (2015c) 17a. Speculum Hebraeorum ou Speculum disputationis contra Hebraeous (Espelho dos hebreus ou (Espelho dos hebreus ou Espelho da disputa contra os hebreus); 17b. Speculum disputationis contra Hebraeos (Espelho da disputa contra os hebreus). In Afonso LU y Miranda A (eds) O livro e a iluminura judaica em Portugal no final da Idade Média. Lisboa: Biblioteca Nacional de Portugal, pp. 143-144.

Tavares A (2017d) Raimundo Lulo e o Livro da Corte Imperial: um exemplar de literatura de polémica judaico-religiosa medieval. In Díaz FJ y Higuera J (eds) En torno a Ramón Llull: presencia y transmisión de su obra. Porto: Húmus, pp. 161-174.

Tavares MJF (1982) Os judeus em Portugal no século XV. Lisboa: Universidad Nueva de Lisboa. Facultad de Ciencias Sociales y Humanas.

Tuthill JG (1982) The sermons of brother Paio: thirteenth century dominican preacher. (Sermons in latin text). PhD Thesis, University of California, USA. 